\title{
Learning networks and communication skills
}

\author{
Kerry Musselbrook,* Erica McAteer,* Charles Crook,** Hamish Macleod*** and \\ Andy Tolmie**** \\ *University of Glasgow, **University of Loughborough, ***University of Edinburgh \\ *****University of Strathclyde \\ email: e.mcateer@udcf.gla.ac.uk
}

The project work presented in this paper is funded by the Joint Information Systems Committee (JISC) January-December 1999. Our task has been to identify effective communicative practices for different technologies, in relation to the contexts in which they occur, and to feed back information about such practices to the educational community in a context-sensitive way. The technologies at issue are: video conferencing (one-to-one, one-to-many, many-to-many); text-based communication (email, bulletin boards, conferencing,) and audio conferencing (telephone tutoring, shared workspace plus audio link). The teaching and learning sites that agreed to take part in this research project provide courses to a variety of learners - undergraduate, postgraduate, professional, full- and part-time - in a spread of subject disciplines. The breadth and range of learning environments represented should maximize the chances of teachers in further and higher education recognizing issues and circumstances that are similar to their own and provide a rich comparative framework. The lecturers from the various teaching sites are regarded as collaborators in this research, identifying their own issues and learning needs, and providing feedback to authenticate the interpretative process. This study approach bridges the practice-theory gap. We have completed the field work and are midway through analysing and interpreting the data in collaboration with teachers and students involved in the study. This will lead to the production of a flexible resource for individual lecturing staff which can also underpin staff development courses in good practice within networked learning environments. Further details and progress updates can be gleaned from our project web site at http://www.gla.ac.uk/services/tls/ JISClindex.html. 


\section{Introduction}

The increase in student numbers in further and higher education over the last decade has been dramatic, placing greater pressures on academic staff in terms of contact hours. At the same time public funding of universities has decreased. Furthermore, the current pace of technological innovation and change and the fact that there are fewer jobs for life with clear pathways for progression mean that more of us need to be engaged in learning throughout our lives in order to remain competitive in the job-market. That is the reality of lifelong learning. Students are consequently demanding (especially as they are having to meet more of the costs of education themselves) a more flexible learning framework. This framework should be able to accommodate all types of learners - part-time, mature, remote and disabled students. The revised Disability Discrimination Act, which came into force in October 1999, only temporarily excludes education from its remit and has already challenged university practices. (Another JISC-funded initiative, Disability Information Systems in Higher Education, addresses just this issue: http://www.disinhe.ac.uk.) All this is set against a backdrop of the government's stated vision for a more inclusive, less élitist education system with opportunities for all, and the requirement for a professional and accountable community of university teachers.

Responses to these challenges have in part focused on modifications to course design, such as modularization with smaller and discrete units allowing for credit accumulation and transfer within and between institutions, including collaboration between further and higher education institutions. There has also been an increased emphasis on collaborative work amongst students, at least partially as a way of reducing teacher contact hours. Finally, and most relevant to our own project, the introduction of communication and information technology (C\&IT) has also been identified as a strategy for meeting these challenges.

A variety of uses of C\&IT have been proposed and developed, but one increasingly important strand of innovation is the use of conferencing technologies which have the potential to enhance dialogue amongst those engaged in learning. Video-conferencing (oneto-one, one-to-many, many-to-many); text-based communication (email, bulletin boards, conferencing,) and audio-conferencing (telephone tutoring, shared workspace plus audio link) are the principal technologies that have emerged to organize these mediated forms of learning conversation. These are the technologies that are the focus of our own research.

\section{Implications for staff development and training}

Such conferencing technologies are not new, but they are relatively new to the further and higher education sectors as tools for teaching and learning. Currently, they could not be described as mainstream or commonplace although there is increasing pressure for them to be assimilated into the learning arena. Clearly it is unrealistic (or at the very least unwise) to expect that conferencing technologies can be introduced without adequate support. The introduction and integration of conferencing technologies has many implications for staff development and training. A central issue in the deployment of such resources to support effective learning is the development, or adaptation of communication skills for the virtual learning environment. It is not always a case of adapting teaching methods to new technologies, but, rather, of developing new methods through their use. Learning tasks or 
student-teacher roles initially complying to more traditional models may be revised by teachers reflecting upon experience with, for example, asynchronous text-based conferencing. Nation and Walker (1993) conceive of staff development and training as a problem of 'converting people who have been reared as learners and teachers in classroom contexts to different forms of practice'.

The aims of our research project are therefore to identify effective communicative practices for different conferencing technologies and feed back information about such practices to the educational community. Teachers working in further and higher education institutions and support staff responsible for developing practice are our main target audience. It is also our hope that our product (a final report and staff development resource rolled into one) will be of use and of interest to network support and C\&IT development groups, education and/or communication researchers as well as policy-makers within higher and further education. Information and support from and to all levels is desirable and necessary if sustainable change is to be achieved.

\section{Theoretical framework}

Changing the tools of learning by introducing conferencing technologies generally requires changes and adaptations in human behaviour for successful communication to take place. There has long been the appreciation that when communication shifts to a different medium there is a loss of some of the audio and/or visual information that would be available in faceto-face encounters. In one of the first systematic attempts to deal with this issue, Rutter, Stephenson and Dewley (1981) argued that the loss of such information results in 'cuelessness', i.e. people feel uncertain about where and when in a conversation they can interject and as a consequence retreat from more spontaneous interaction, focusing to a greater degree on the basic message at the expense of developing a broader shared understanding. People find ways to compensate for these limitations, however, and discover ways of reinstating information that would be available face-to-face. An obvious example of this is the use of 'emoticons' to signal attitudinal or emotional information in an email message. Other recent research, carried out in real-life settings, supports our basic contention that people do learn to adapt to new technologies and, moreover, adapt their uses of these better to meet their teaching or learning purpose (CoSHEP, 1998; Isaacs and Tang, 1997; O'Connail and Whittaker, 1997; Sellen, 1997; Yates, 1997, Whittaker and O'Connail, 1997).

This is not to argue, however, that developing good communication skills for conferencing is simply a matter of developing strategies for compensation. Conferencing technologies also have their 'affordances', a term first applied to the use of electronic media by Gaver (1992). Affordances are properties of an object or system which enable certain actions or functions to be performed more readily than others (Gibson, 1966). The affordances of conferencing technologies remediate and reshape the teaching and learning environment. Whilst it can be argued that the technology interposes between direct person to person interaction, it may actually create a shared environment that shapes the process of interpersonal communications (Dede, 1991).

It is our starting position that the limitations and affordances of conferencing technologies require adaptations and changes in human behaviour for successful communication to take place. Adaptations and the development of new skills and strategies generally happen over 
a period of time. They also happen in response to, and in service of, a specific task, that is, an identified need (Leont'ev, 1981; 1978; Engstrom, 1987; Lewis, 1997).

Accepting this approach, the means of communication should not be treated as something separate in communicators' minds from the content in which the communication takes place or indeed the context (Cole, 1996). Teaching and learning does not happen in a vacuum; we contend that every teaching and learning domain has its own unique configuration which needs to be acknowledged. This might encompass the capabilities/ functionality of the technology in question, the persons using it to communicate, cultural and environmental factors, and the nature and content of the message(s) relayed. The aims and objectives of every course and the tasks it includes are also unique. Clearly the success of any communication and the measure of 'good' educational practice is contingent upon and defined by the aims and objectives as they are perceived.

Existing approaches often assume that adaptation to new technologies is simply a matter of defining and acquiring a generic set of skills. The research team refutes the notion, however, that a generic set of skills can be identified or acquired to meet the needs of all users of conferencing technologies in a range of teaching and learning environments. Instead, it is our contention that adapting to or learning how to use conferencing technologies effectively is activity-based, context-specific and situated - as, one would argue, is all effective teaching and learning.

\section{Methodological design, data collection, analysis and dissemination}

The framework outlined above informed the design of our research and the methodology adopted. If adaptations to technology are situated in the domain and purpose of its everyday use, there is no point looking for them in artificial or laboratory settings (or feeding back this information in an abstract, context-free mode). We therefore opted to examine and present findings from real cases, drawn from a range of teaching and learning sites with two or more years' experience of incorporating conferencing technologies into their teaching.

\section{The teaching sites}

It is our hope that the range of cases will increase the likelihood of teachers in the further and higher education community recognizing circumstances and issues that are similar to their own. A breakdown of the courses offered by sites participating in this study is given in Table 1. The courses listed in Table 1 were based at a variety of institutions including traditional and post-1992 universities, the Open University and a number of the colleges which form part of the new University of the Highlands and Islands.

A variety of subject disciplines, undergraduate and postgraduate courses are represented, where conferencing technologies are an 'interesting add on', or are one of several teaching and learning components, or are essential to the actual functioning of the course. Conferencing technologies might be essential if they provide the only means for interaction and discussion as part of a distance education course, or they enable the grouping of a sufficient number of students to make a course or module viable and cost-effective to run. In some cases conferencing technologies have been the focus of students' studies as well as the means of delivery or a channel for communicating. Product design students using the 


\begin{tabular}{|c|c|c|}
\hline Course(s) & Students & Conferencing technology \\
\hline Product Design Engineering/Design & third-year undergraduates & video-conferencing, text-based \\
\hline $\begin{array}{l}\text { Politics and International Relations/Politics. } \\
\text { Philosophy and Economics }\end{array}$ & \multicolumn{2}{|c|}{ postgraduate students studying for their MA video-conferencing } \\
\hline $\begin{array}{l}\text { Various courses in different disciplines, } \\
\text { often shared across UHIP college sites }\end{array}$ & $\begin{array}{l}\text { postgraduate, undergraduate, CPD, } \\
\text { HNC/HND }\end{array}$ & video-conferencing \\
\hline Physics and Environmental Sciences & $\begin{array}{l}\text { final-year undergraduates and } \\
\text { postgraduate students }\end{array}$ & video-conferencing \\
\hline Introduction to Cultural Studies Module & first-year undergraduates & text-based conferencing \\
\hline $\begin{array}{l}\text { MA in Education. Computer Mediated } \\
\text { Communication Module }\end{array}$ & postgraduate students & text-based conferencing \\
\hline Masters in Open and Distance Education & $\begin{array}{l}\text { postgraduate students (professional } \\
\text { development) }\end{array}$ & text-based conferencing \\
\hline Applied Psychology and Computing & third-year undergraduates & text-based conferencing \\
\hline Psychology and information Technology & fourth and final year undergraduates & text-based conferencing \\
\hline Level One Biology Modules & undergraduate students & text-based conferencing \\
\hline \multicolumn{3}{|l|}{ Level Two Biology Modules } \\
\hline \multicolumn{3}{|l|}{ Honours classes, various } \\
\hline Automotive Systems Engineering & $\begin{array}{l}\text { postgraduate students studying for } \\
\text { their MSc }\end{array}$ & text-based conferencing \\
\hline Educational Psychology & $\begin{array}{l}\text { postgraduate students studying for } \\
\text { their MSc }\end{array}$ & text-based conferencing \\
\hline $\begin{array}{l}\text { various distance education courses, but } \\
\text { including Science, Arts and Social Science, } \\
\text { and vocational courses }\end{array}$ & Various & audio-conferencing \\
\hline
\end{tabular}

Toble 1: Courses offered by sites participating in the study.

ICON interface, for example, saw themselves as using the tools of their future profession (http://cvu.strath.ac.uk/courseware/cvds2/visitors/icon1.html).

\section{Data collection}

To look simply at specific communicative behaviours in isolation from their context and the aims and objectives of the learning task or course would ultimately be unhelpful. The critical issue is the extent to which users of the technology (teachers and students) understand what the activity is for, and what their objectives are. It was therefore essential to take a phenomenographic approach (Marton, 1981; 1982; 1994) and interview staff and students about perceived objectives, and hear their stories about the success or failure of different communicative strategies - which may or may not have been consciously adopted. Potential disharmony between students' and teachers' models of learning and their views on learning aims and objectives are unlikely to be captured in any other way, as are possible mismatches between sender and recipient on the meaning of communicative content. Furthermore, much communication takes place offline as well as on and may not be captured for posterity on audio or video tape, or as an archive of a text-based conference. Content analysis of a text can help describe it but it cannot always or accurately reveal the impact of one message in relation to another. Observing the conferencing technologies in use and gaining access to archive data - tapes of telephone conferences, video conferences, and archives of text-based conferences - did provide useful insights, however. They allowed 
members of the research group to become familiar with the learning environments concerned and helped to deepen our understanding of the issues raised by students and teachers during interviews.

The initial stages of each interview explored the topic area and allowed the interviewees to describe and evaluate their experiences of text-based conferencing, video conferencing or audio conferencing in their own words. The issues that they thought were important were allowed to emerge using a critical incident approach to the investigation although the interviewer was free to probe and to ask for clarification where necessary. Interviewees were asked to recall instances where communication was particularly successful and particularly unsuccessful and give their understanding of the reasons for this. Where it was possible archives were used to situate and stimulate the interviewees. Students who were interviewed about text-based conferencing, for example, were given the opportunity to access and refer to the conferences in question to illustrate, check and qualify their comments. Students and teachers who were interviewed about video conferencing were played a randomly-selected section from a video conference they had attended or given if archive footage existed. In a few instances student focus groups were arranged to follow on from a video conference that the researcher had also attended and observed. Open University students and teachers with experience of telephone conferencing were interviewed by telephone.

\section{Analysis and dissemination}

Due in part to the sheer volume of our interview data, most of the original tape recordings were digitized, organized by case and stored on CDs. These CDs along with the archive data that we have described were then made available to all five members of the research group for analysis at a 'scanning and sampling' level. A preliminary set of issue codes were debated and agreed upon by all members of the research team to provide a framework for future analysis. After preliminary analysis responsibility for drafting the case summaries was divided among the five members of the research group although we continued to check, develop and share our understandings with one another as part of a triangulating team investment. We plan to adopt the same approach to drafting narrative essays which deal with themes that are common across the educational contexts and technologies. These will be drawn from the range of case summaries, which provide scope for comparative analysis, and from the current literature.

The recursive and iterative principles that have been described characterized our methodology in one other respect. At key points during analysis and write-up of the case summaries and narrative themes we invited feedback from the teaching sites participating in the research in order that all parties could deepen and share their understanding of the issues and needs of the educational community. This collaborative-type approach was built into our methodology to help bridge the practice-theory gap.

\section{The final document - a staff development resource}

Our final report will be a Web-based hypertext document containing:

- a range of case summaries;

- narrative essays on overarching themes; 
- links to existing practice guidelines;

- links to other information sources - e.g. JISC, UKEARNA, GLTC and pages on copyright and IPR advice.

As already mentioned, the case summaries are intended to present readers with information in a context-sensitive and therefore meaningful way. From those case summaries and our review of the current literature, narrative essays on overarching themes will be drawn in an attempt to provide a broader interpretative framework.

Both the case studies and the narrative essays will be illustrated by notes from the literature, examples from the archives and sound-bites from the interviews. These will be stored in a database and accessed by clicking on links in the case studies and narrative essays, bringing the document to life.

The hypertext document is intended for use by individuals, institutions and by staff development centres. Users and readers can choose between various points of entry and follow different pathways according to their particular needs and interests.

\section{Conclusion}

The introduction of conferencing technologies has in part been in response to demands for more flexible learning in the context of lifelong learning. Advocates of the technologies also stress that they can, in certain circumstances and with adequate support, improve as well as alter teaching and learning practice. The use of conferencing technologies in further and higher education could not be described as mainstream or commonplace but their use is increasing, as are pressures for them to be assimilated into the learning arena. The introduction and integration of conferencing technologies has many implications for staff development and training.

Resource materials and courses of a 'how-to' variety already exist within our institutions, addressing the cultivation of the technical skills needed to use conferencing technologies in teaching and learning. However, an approach which addresses 'how-to' while failing to engage with 'why' or how the introduction of a new technology is likely to create a paradigm shift is incomplete and unlikely to take things forward. The task that we set ourselves was to identify effective communication practices and strategies for different conferencing technologies and to feed back this information to the educational community. It is our position and the position of activity theorists that adaptations in behaviour or the development of communication skills and strategies happen in response to and in service of a specific task. This paper argues that the means of communication should not be treated as something separate in peoples' minds from content or context. If it is true that adaptations to new technologies are situated, there is clearly no point in looking for them in artificial settings. By the same token there is little point in feedback information to the educational community in an abstract way if the information is to remain meaningful.

We therefore opted to examine and present findings from a range of real cases. These cases were drawn from a range of higher and further education institutions. The lecturers at these institutions provided courses in a spread of subject disciplines to a variety of learners - undergraduates, postgraduates, professional, full- and part-time students. It is our hope that by presenting a range of case summaries, the report will increase the likelihood of 
teachers recognizing circumstances and issues that are similar to their own. This is not to say, however, that narrative themes common across different conferencing technologies and contexts cannot be developed to provide a broader interpretative framework. The final staff development resource that we currently envisage will incorporate case summaries, narrative themes and other useful links to form a hypertext document with different points of entry and pathways through it to suit individuals' learning needs.

The collaborative and iterative approach which we have adopted throughout this research project, both within the research group and with the various teaching sites, should ensure that the needs of the educational community are understood and served to the best of our ability. We are hopeful that our methodology can help to bridge what is commonly referred to as the practice-theory gap.

\section{Acknowledgements}

The authors would like to thank the Joint Information Systems Committee for funding this research project as part of their CALT (Committee for Awareness of Learning and Teaching) Networked Learning Initiative. We owe much to the teachers, support staff and students at our collaborative sites, to colleagues concerned in the development of good practice with conferencing technologies across the HE sector and, particularly, to participants in our ALT-C session for their input, then and afterwards.

\section{References}

Clark, H. H. and Brennan, S. E. (1993), 'Grounding in communication', in Resnick, L. B., Levine, J. M. and Teasley, S. D. (eds.), Perspectives on Socially Shared Cognition, American Psychology Association, Washington DC, 127-49.

Cole, M. (1996), Cultural Psychology: A Once and Future Discipline, Harvard University: Belknap Press.

CoSHEP (1998), Workshop series in collaboration with TALiSMAN initiative, UHIP presentation, May 1998.

Dede, C. J. (1991), 'Emerging technologies: impacts on distance learning', ANNALS APPSS, 514, 146-58.

Engestrom, Y. (1987), Learning by Expanding: An Activity-Theoretical Approach to Developmental Research, Helsinki: Orienta-Konsultit.

Gaver, W.W. (1992), 'The affordances of media spaces for collaboration', CSCW '92: Sharing Perspectives. Proceedings of the Conference on Computer Supported Cooperative Work, Toronto.

Gibson, J. J. (1966), The Senses Considered as Perceptual Systems, Boston: HoughtonMifflin.

Isaacs, E. A. and Tang, J. C. (1997), 'Studying video-based collaboration in context: from small workgroups to large organizations', in Finn, K. E., Sellen, A. J. and Wilbur, S. B. (eds.), Video-Mediated Communication, Mahwah, NJ: Lawrence Erlbaum Associates, 173-97. 
Leont'ev, A. N. (1978), Activity, Consciousness, and Personality, Englewood Cliffs: Prentice Hall.

Leont'ev, A. N. (1981), Problems of the Development of the Mind, Moscow: Progress.

Lewis, R. (1997), 'An activity theory framework to explore distributed communities', Journal of Computer Assisted Learning, 13 (4), 210-18.

Marton, F. (1981), 'Phenomenography - describing conceptions of the world around us', Instructional Science, 10, 177-200.

Marton, F. (1982), Towards a Phenomenography of Learning. III. Experience and Conceptualisation, Reports from the Department of Education, University of Gothenburg, 1982,8 .

Marton, F. (1994), 'Phenomenography', in Husen, T. and Postlethwaite, N. (eds.), International Encyclopaedia of Education, Oxford: Pergamon, 4424-9.

Nation, D. and Walker, R. (1993), 'Course development without instructional design', in Parer, M. (ed.), Developing Open Courses, Centre for Distance Learning, Monash University, Victoria, Australia, 99-129.

O'Connaill, B. and Whittaker, S. (1997), 'Characterizing, predicting, and measuring videomediated communication: a conversational approach', in Finn, K. E., Sellen, A. J. and Wilbur, S. B. (eds.), Video-Mediated Communication, Mahwah, NJ: Lawrence Erlbaum Associates, 106-31.

Rutter, D. R., Stephenson, G. M. and Dewley, M. E. (1981), 'Visual communication and the content and style of conversation', British Journal of Social Psychology, 20, 41-52.

Sellen, A. and Harper, R. (1997), 'Video in support of organizational talk', in Finn, K. E., Sellen, A. J. and Wilbur, S. B. (eds.), Video-Mediated Communication, Mahwah, NJ: Lawrence Erlbaum Associates, 225-43.

Whittaker, S. and O'Connaill, B. (1997), 'The role of vision in face-to-face and mediated communication', in Finn, K. E., Sellen, A. J. and Wilbur, S. B. (eds.), Video-Mediated Communication, Mahwah, NJ: Lawrence Erlbaum Associates.

Yates, S. J. (1997), 'Gender, identity and CMC', Journal of Computer Assisted Learning, 13, $281-90$. 